\title{
Pleural Effusion due to Mesothelioma in a Dog-A Case Report
}

\author{
K. Mohanambal*, Aswathi Mohan, S. Rajyalakshmi and G. Vijayakumar \\ Department of Veterinary Clinical Medicine, \\ Veterinary College and Research Institute, Namakkal - 637002 \\ (Tamil Nadu Veterinary and Animal Sciences University, Chennai-600 051) \\ Tamil Nadu, India \\ *Corresponding author
}

\section{A B S T R A C T}

\begin{tabular}{l} 
Ke y w o r d s \\
$\begin{array}{l}\text { Mesothelioma, } \\
\text { Thoracocentesis, } \\
\text { Echocardiography }\end{array}$ \\
\hline Article Info \\
\hline $\begin{array}{l}\text { Accepted: } \\
18 \text { May } 2020 \\
\text { Available Online: } \\
\text { 10 June } 2020\end{array}$ \\
\hline
\end{tabular}

Objective: A male Spitz about 7 years was presented to Veterinary College and Research Institute hospital with severe respiratory distress and anorexia for 3 days, which was successfully managed with thoraccocentesis. Case summary: Clinical examination revealed paradoxic respiration, dyspnoea, oral breathing and abducted elbows. Thoracic radiography revealed pulmonary infiltration with unclear cardiac silhouette. Electrocardiogram and echocardiography revealed arrhythmia and pleural effusion with dilated cardiac myopathy respectively. Thoracocentesis was done to relieve respiratory distress. Cytology of pleural fluid revealed mesothelioma. Animal was treated with enalapril, furosemide, prednisolone and pantaprazole. Animal showed significant clinical improvement following treatment. Unique information: Thoraccocentesis is the lifesaving emergency procedure which should be done in cases having paradoxic respiration.

\section{Introduction}

Mesothelioma is an uncommon tumour in dogs which are of low grade malignancy (Vural et al., 2007). They originate from the mesothelial cells covering the coelomic cavities such as pericardium, pleura, peritoneum and vaginal tunic. Effusions are one of the most common classic characteristic of mesothelioma. Pleural effusion is the accumulation of fluid within the pleural space. Normal pleural cavity has 2-3 $\mathrm{ml}$ of fluid. An increase in hydrostatic pressure is caused by conditions such as cardiomyopathy, neoplasia, cardiac tamponade, heartworm disease etc. (Ulgen et al., 2015). This results in increased formation and decreased resorption of pleural fluids, leading to formation of pleural effusions. 


\section{Case history and observation}

A 7 year old male Spitz weighing $6.9 \mathrm{~kg}$ was brought with the history of respiratory distress and anorexia for the past 3 days. Clinical examination revealed that the animal had dyspnoea, paradoxic respiration, oral breathing and abducted elbows. Haematology revealed leucocytosis with neutrophilia. Radiography showed ground glass appearance and unclear cardiac silhouette. Electrocardiography revealed arrhythmia. Echocardiography showed anaechoic fluid around the heart in the thoracic cavity. Thoracocentesis was performed and around $200 \mathrm{ml}$ of serosanguinous viscous fluid was collected which was found to be a modified transudate. Cytological examination revealed cluster of mesothelial cells with prominent nuclear vacuolation and higher nucleus to cytoplasm ratio indicative of mesothelioma.

\section{Treatment and Discussion}

Thoracocentesis was the prime treatment given to animal since this relieves respiratory distress and also provides time for cyotological examination (Martins et al., 2011). The dog was treated with Angiotensin Converting Enzyme (ACE) inhibitor enalapril (@0.5mg/kg/day, PO), diuretic furosemide (@ 4mg/kg PO), corticosteroid prednisolone (@ 0.5mg/kg, PO) along with pantaprazole (@2 mg/kg PO) for 10 days. Angiotensin Converting Enzyme inhibitors act by lowering peripheral vascular resistance without causing an increase in heart rate. Furosemide, by its diuretic action, helps in removal of the pleural effusions. Prednisolone has tumor suppressive properties. Animal was found to be active and was showing reduced respiratory distress after treatment. Cytological examination revealed cluster of mesothelial cells (Mohenambal et al., 2019). Echocardiographic examinatin on $4^{\text {th }}$ day revealed reduced quantity of anechoic fluid while radiography showed clear cardiac silhoutte. Left ventricular internal diameter (LVID) value of $37.1 \mathrm{~mm}$ which was more than normal range $22.71-24.76 \mathrm{~mm}$ for dogs of $6.8 \mathrm{~kg}$ body weight (Boon et. al., 1983) indicated cardio myopathy. Treatment with frusemide (@4mg/kg PO), enalapril (@ $0.5 \mathrm{mg} / \mathrm{kg} /$ day, PO) and pimobendan was carried out. The dog had appreciable clinical improvement following initiation of treatment.

Treatment for mesothelioma and dilated cardio myopathy was carried out and the dog showed appreciable clinical improvement following initiation of treatment.

\section{References}

Boon J, Wingfield WE, Miller AW. Echocardiographic indices in the normal dog. Vet radiol 1983; 24(5): 214-221.

Martins DB, Souza GS, Pedroso JCSR, Mazzantia CM.Thoracic and abdominal mesothelioma in a dog: A cyotogist's view. Comp Clinical Pathol., 2011; 20: 289-293.

Mohanambal, K, Vijayakumar G, Ravi R, Sivaraman S, Sudhakara Reddy B, Madheswaran R. A Rare Case of Mesothelioma in a Kangayam Bull- A Case Report. Indian Vet J2019; 96(02): 77- 78.

Ulgen S, Bakirel U, Yildiz K, Yildirim F, FiratI. Pleural Effusion in a Dog with Mesothelioma. Journal of Life Sciences 2015; 9: 362-365.

Vural SA, Ozyildiz Z, Ozsoy SY.Pleural mesothelioma in a nine-month-old dog. IrVet J 2007; 60(1): 30-33. 


\section{How to cite this article:}

Mohanambal, K., Aswathi Mohan, S. Rajyalakshmi and Vijayakumar, G. 2020. Pleural Effusion due to Mesothelioma in a Dog- A Case Report. Int.J.Curr.Microbiol.App.Sci. 9(06): 1512-1514. doi: https://doi.org/10.20546/ijcmas.2020.906.186 